\title{
The effect of using a methanol-water solvent mixture on pH oscillations in the palladium-catalyzed phenylacetylene oxidative carbonylation reaction
}

\author{
Julie Parker ${ }^{1}$ (D) Katarina Novakovic ${ }^{1}$
}

Received: 18 August 2017/Accepted: 24 September 2017/Published online: 30 September 2017

(C) The Author(s) 2017. This article is an open access publication

\begin{abstract}
The palladium-catalyzed phenylacetylene oxidative carbonylation reaction has been shown to produce regular oscillations in $\mathrm{pH}$, reaction heat, and turbidity when conducted in batch with methanol as solvent. Previous studies of the catalytic system showed that water plays an important role in the behavior of the catalytic cycle. Investigating this role further, the reaction was performed in methanol-water mixtures. Experiments demonstrated that, under the conditions studied, oscillations in $\mathrm{pH}$ are feasible when the water concentration in the system is increased (0-30 V\%). At the same time oscillations visually changed, being transformed from regular oscillations to more stepwise behavior as the proportion of water is increased. By establishing the relationship between the recorded $\mathrm{pH}$ and $\mathrm{HI}$ concentration it was found that increased water concentration suppresses HI formation and hence slows the autocatalysis in the reaction. It was also found that oscillations begin when the $\mathrm{HI}$ concentration is in the region of $1 \times 10^{-3} \mathrm{~mol} \mathrm{~L}^{-1}$. Additionally, as the amount of water in the system increases a slight decrease in the concentration of $\mathrm{HI}$ when oscillations start was noted.
\end{abstract}

Keywords Oscillatory reaction $\cdot \mathrm{pH} \cdot$ Carbonylation $\cdot$ Calorimetry $\cdot$ Water/ methanol mixture

\section{Introduction}

Carbonylation reactions are $\mathrm{C}-\mathrm{C}$ bond forming reactions that are particularly important for organic synthesis. The carbonylation of phenylacetylene in methanol (Scheme 1), producing the isomeric diesters dimethyl (2Z)-2-phenyl-2-butenedioate

Julie Parker

julie.parker@ncl.ac.uk

1 School of Engineering, Newcastle University, Newcastle upon Tyne NE1 7RU, England, UK 


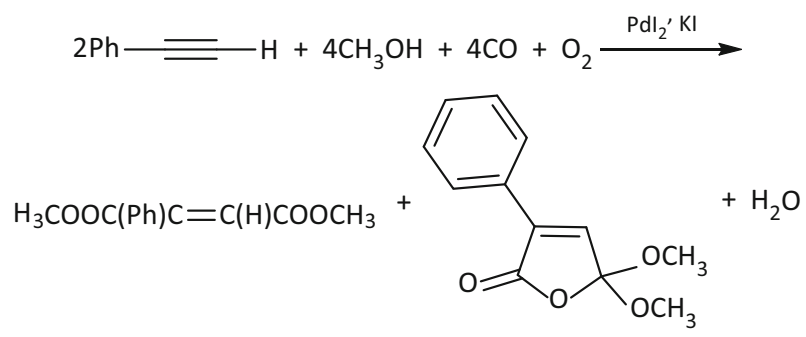

Scheme 1 The palladium-catalyzed carbonylation of phenylacetylene in methanol

and dimethyl (2E)-2-phenyl-2-butenedioate as well as 5,5-dimethoxy-3-phenyl$2(5 \mathrm{H})$-furanone, has been shown to produce oscillations in $\mathrm{pH}$, redox potential and reaction heat [1-3].

The oscillatory nature of changes in $\mathrm{pH}$ and reaction heat during the palladiumcatalyzed phenylacetylene oxidative carbonylation (PCPOC) reaction has opened this reaction up to new areas of study and possible applications [4, 5]. One of the interesting observations made during previous investigations of the $\mathrm{PCPOC}$ reaction at temperatures from 0 to $40{ }^{\circ} \mathrm{C}$ was the effect adding methanol to the reaction mixture had on the period and amplitude of the $\mathrm{pH}$ oscillations. Without exception, the addition of methanol caused the period and amplitude of the $\mathrm{pH}$ oscillations to increase and even appeared to restart oscillations when they had previously ceased $[6,7]$. Perturbation studies by Mukherjee found that the addition of HPLC grade methanol to the reaction system when large sustained oscillations were present caused a slight increase in the period of the oscillations, however, when anhydrous methanol was used as both reactant and solvent the reaction did not exhibit any meaningful $\mathrm{pH}$ oscillations [8]. As the methanol was in huge excess relative to the other reactants, it is unlikely to be responsible for these observations. The most likely cause is the trace water found in the HPLC methanol (stated as $<0.03 \%$ by Sigma-Aldrich) used in the experiments. Water has been shown to affect the behavior of the catalytic system used in the PCPOC reaction and is therefore proposed to be involved in the processes in the reaction mechanism that produce the $\mathrm{pH}$ oscillations [9, 10]. Water also reacts in a similar manner to methanol (Scheme 1) leading to the isomeric diacids [(2Z)-2-phenyl-2-butenedioic acid and (2E)-2-phenyl-2-butenedioic acid] and phenylmaleic anhydride [11].

In this study, a series of experiments in which the water concentration was increased from 0 to $40 \mathrm{~V} \%$ were conducted at $30{ }^{\circ} \mathrm{C}$. This temperature was selected as being within the interval that previously demonstrated oscillatory $\mathrm{pH}$ behavior for the PCPOC system. In previously reported results, this temperature gave $\mathrm{pH}$ oscillations with a maximum period of $45 \mathrm{~min}$ and a reaction time of $3600 \mathrm{~min}$ when compared to lower temperature runs that exhibited oscillatory behavior that lasted for several weeks [7, 12, 13]. All experiments were carried out in an HEL Simular reaction calorimeter so that changes in $\mathrm{pH}$ and reaction heat $\left(\mathrm{Q}_{\mathrm{r}}\right)$ could be monitored continuously for extended periods of time. To understand the effect of solvent composition on the $\mathrm{pH}$ recorded in the experiments, a separate set of titrations was performed to relate the $\mathrm{pH}$ measured as a function of hydroiodic acid 
(HI) concentration as $\mathrm{HI}$ is considered to be the reaction product responsible for the $\mathrm{pH}$ oscillations. The results of these titrations were used to estimate the concentration of $\mathrm{HI}$ that corresponded to the $\mathrm{pH}$ recorded in this study.

\section{Experimental}

\section{PCPOC experiments}

Experiments on the reaction system were conducted using an HEL Simular reaction calorimeter comprising of: a $1 \mathrm{~L}$ double jacketed reactor connected to a Julabo heater/circulator; a combined $\mathrm{pH}$ electrode; Pt100 temperature probe; a $150 \mathrm{~W}$ internal electric heater and 2 mass flow controllers to dose $\mathrm{CO}$ and air. All chemicals were purchased from Sigma-Aldrich and used as received. The reaction temperature was set at $30{ }^{\circ} \mathrm{C}$ with deionized water volume percent of $0,5,20,30$ and $40 \%$. The solvent (approximately $400 \mathrm{~mL}$, with the required composition of Chromasolv HPLC grade methanol $(\mathrm{MeOH})$ and deionized water as shown in Table 1) was added to the reactor.

The solvent mixture was heated to $30^{\circ} \mathrm{C}$ while stirring at $250 \mathrm{rpm}$ and palladium(II) iodide (434 mg) was added. The mixture was stirred for 35 min then $114 \mathrm{mg}$ of NaOAc and $37.392 \mathrm{~g}$ of KI were added along with approximately $30 \mathrm{~mL}$ of the solvent mixture to remove any solids remaining on the reactor walls. The stirrer speed was increased to $350 \mathrm{rpm}$ to increase the rate of KI dissolution. After $10 \mathrm{~min}$, the internal standard naphthalene $(1.154 \mathrm{~g})$ was added followed by a further $20 \mathrm{~mL}$ of solvent of the required methanol/water composition. The stirrer speed was returned to $250 \mathrm{rpm} 5 \mathrm{~min}$ after adding the naphthalene. The purging of the reaction mixture with $\mathrm{CO}\left(50 \mathrm{~mL} \mathrm{~min}{ }^{-1}\right)$ and air $\left(50 \mathrm{~mL} \mathrm{~min}^{-1}\right)$ commenced and continued for the duration of the experiment. Phenylacetylene $(6.2 \mathrm{~mL})$ was added after the solution had been purged with $\mathrm{CO}$ and air for $20 \mathrm{~min}$. Temperature and $\mathrm{pH}$ were monitored throughout each experiment with additional solvent of the required methanol/water composition added as necessary to compensate for evaporative loss.

\section{Determination of relationship between $\mathrm{pH}$ measured and $\mathrm{HI}$ present in the system}

The relationship between $\mathrm{pH}$ and $\mathrm{HI}$ concentration was established for each solvent composition at $30{ }^{\circ} \mathrm{C}$. A dilute stock solution of $\mathrm{HI}$ in methanol was prepared by

Table 1 Composition of solvents used to dissolve KI $(37.392 \mathrm{~g})$ in all experiments

\begin{tabular}{lcl}
\hline Vol percent of $\mathrm{H}_{2} \mathrm{O}(\%)$ & Vol of $\mathrm{H}_{2} \mathrm{O}(\mathrm{mL})$ & Vol of $\mathrm{MeOH}(\mathrm{mL})$ \\
\hline 0 & 0 & 450 \\
5 & 22.5 & 427.5 \\
20 & 90 & 360 \\
30 & 135 & 315 \\
40 & 180 & 270 \\
\hline
\end{tabular}


weighing $50 \mu \mathrm{L}$ of $57 \% \mathrm{HI}$ solution in water in a $5 \mathrm{~mL}$ volumetric flask and then filling the flask up to the mark with Chromasolv HPLC grade methanol. A $75 \mathrm{~mL}$ aliquot of the required methanol/water/KI solution (Table 1) was transferred to a $100 \mathrm{~mL}$ conical flask which was subsequently kept in a water bath held at $30{ }^{\circ} \mathrm{C}$ for the duration of the experiment. Potassium iodide was included as it is used in a large excess in the PCPOC reactions to dissolve $\mathrm{PdI}_{2}$. This means that the ionic strength of the reaction mixture is high (approximately $0.5 \mathrm{~mol} \mathrm{~L}^{-1}$ ). Ionic strength can affect the $\mathrm{pH}$ electrode liquid junction potential and the hydrogen ion activity $[14,15]$. The large excess of $\mathrm{I}^{-}$will also affect the dissociation of HI. Including KI in the experiments to determine the relationship between the $\mathrm{pH}$ measured and the $\mathrm{HI}$ present in the system allowed the $\mathrm{pH}$ measurements to more accurately reflect those obtained during the PCPOC experiments. The calibrated $\mathrm{pH}$ electrode and Pt100 temperature probe from the HEL calorimeter were placed in the flask to monitor $\mathrm{pH}$ and temperature. Portions of the dilute HI solution were added gradually to the methanol/water/KI solution starting with $10 \mu \mathrm{L}$ allowing the $\mathrm{pH}$ to stabilize between each addition. After $1 \mathrm{~mL}$ of dilute HI solution had been added the $57 \mathrm{wt} \% \mathrm{HI}$ solution was used to continue the experiment.

\section{Results and Discussion}

The $\mathrm{pH}$ recorded in the phenylacetylene carbonylation experiments employing HPLC grade methanol and methanol/water mixtures is given in Fig. 1. In the experiment using $100 \%$ methanol, the addition of $\mathrm{PhAc}$ to the reactor containing the rest of the catalyst components $\left(\mathrm{PdI}_{2}, \mathrm{KI}\right.$ and $\left.\mathrm{MeOH}\right)$ resulted in a drop in $\mathrm{pH}$ from 7.5 to a $\mathrm{pH}$ of 1 before the $\mathrm{pH}$ slowly increased and oscillations began. As the

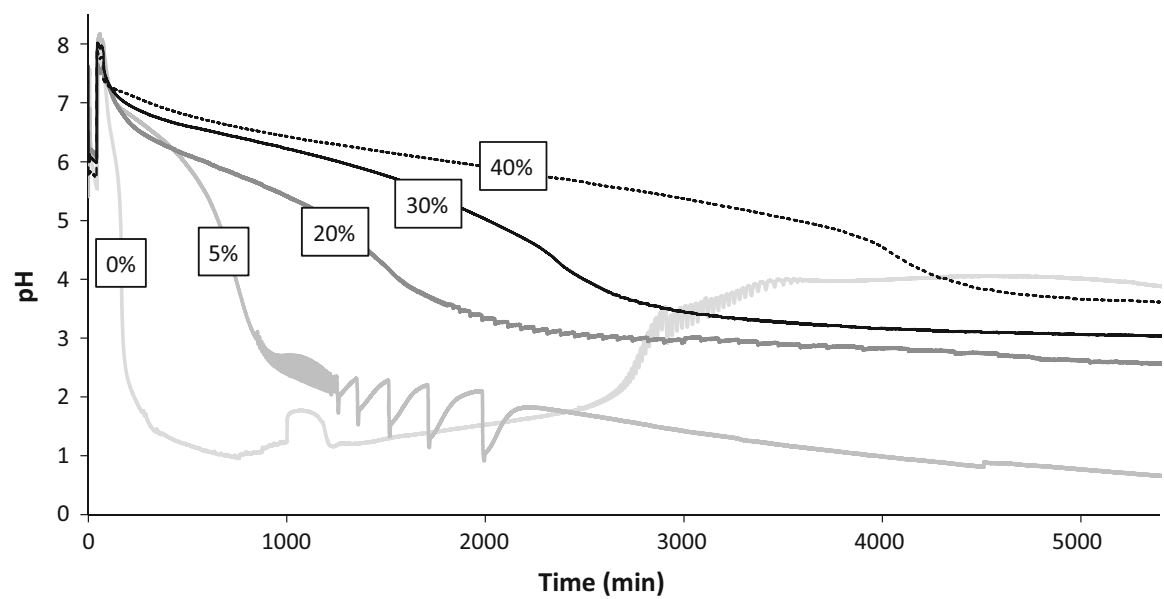

Fig. 1 Comparison of $\mathrm{pH}$ behavior in the PCPOC reaction at $30^{\circ} \mathrm{C}$ with water volume percentage from 0 to $40 \%$ with $[\mathrm{PhAc}]=0.124 \mathrm{~mol} \mathrm{dm}{ }^{-3}\left[\mathrm{PdI}_{2}\right]=2.64 \times 10^{-3} \mathrm{~mol} \mathrm{dm}^{-3}[\mathrm{KI}]=0.494 \mathrm{~mol} \mathrm{dm}^{-3}$ $[\mathrm{NaOAc}]=3.05 \times 10^{-3} \mathrm{~mol} \mathrm{dm}^{-3} \mathrm{CO}=50 \mathrm{~mL} \mathrm{~min}^{-1}$ and air $=50 \mathrm{~mL} \mathrm{~min}^{-1}$ 
amount of water in the system was increased the initial fall in $\mathrm{pH}$ took longer, oscillations commenced while $\mathrm{pH}$ was decreasing and $\mathrm{pH}$ did not recover (Fig. 1).

The $\mathrm{pH}$ oscillations for each solvent composition are shown in Figs. 2 and 3. The $\mathrm{pH}$ oscillations in Fig. 2 were taken as the baseline $\mathrm{pH}$ behavior $(100 \% \mathrm{MeOH})$ to which the $\mathrm{pH}$ behavior in the other solvent compositions could be compared. In $100 \% \mathrm{MeOH}$, the $\mathrm{pH}$ dropped rapidly after $\mathrm{PhAc}$ addition and then rose slowly over the next 1700 min (Fig. 1). When the $\mathrm{pH}$ reached 1.5, after $2421 \mathrm{~min}$, oscillations began. Once oscillations started the rate at which the $\mathrm{pH}$ rose increased and the $\mathrm{pH}$ oscillations gradually increased in period and amplitude (Fig. 2). The rate of the $\mathrm{pH}$ increase then slowed at 2900 min until the oscillations stopped.

The trends in the $\mathrm{pH}$ oscillations are summarized in Table 2 which shows the amplitude of the oscillations decreased as the amount of water in the system increased. Table 2 also shows that increasing the water volume percent of the system from 5 to $30 \%$ delayed the onset of oscillations, with the change from 5 to $20 \%$ taking $60 \%$ longer before oscillations occur whilst going from 5 to $30 \%$ takes almost 3 times longer for oscillations to start. The increase in water content also increased the duration of the oscillations from $1149 \mathrm{~min}$ (volume percent $5 \%$ ) to 3122 min (volume percent 30\%).

The $\mathrm{pH}$ oscillations for the experiment in which the water volume percent was $5 \%$ are shown in Fig. 3a. It shows the onset of $\mathrm{pH}$ oscillations occurred when the $\mathrm{pH}$ was falling and much earlier (845 min) than in the baseline experiment conducted in $100 \% \mathrm{MeOH}$. Initially the shape of the oscillations was similar to that occurring in $100 \% \mathrm{MeOH}$ (Fig. 2) with a similar period (9 min) and amplitude (0.4 pH units). Note the switching of the oscillatory behavior which occurred after $1245 \mathrm{~min}$ producing the large relaxation oscillations (Fig. 3a). This was not due to any deliberate perturbation of the system and was repeatedly noted in experiments under the same initial conditions. This may mark a transition from one oscillatory state to another.

Drastically smaller oscillations were captured in the experiment employing a water volume percent of $20 \%$ (Fig. 3b). When a water volume percent of $5 \%$ was used, the oscillations occurred when the $\mathrm{pH}$ was falling. Oscillations commenced at 1351 min when $\mathrm{pH}$ was 4.35 and lasted for 2876 min with $\mathrm{pH}$ settling at a $\mathrm{pH}$ of

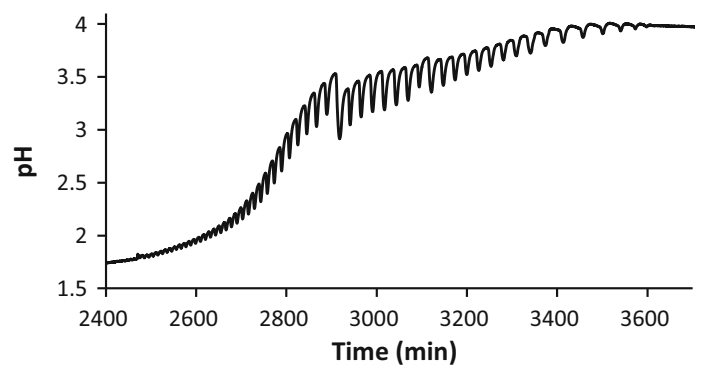

Fig. $2 \mathrm{pH}$ oscillations in the PCPOC reaction at $30{ }^{\circ} \mathrm{C}$ in $100 \% \mathrm{MeOH}$ with $[\mathrm{PhAc}]=0.124 \mathrm{~mol} \mathrm{dm}^{-3}$ $\left[\mathrm{PdI}_{2}\right]=2.64 \times 10^{-3} \mathrm{~mol} \mathrm{dm}^{-3}[\mathrm{KI}]=0.494 \mathrm{~mol} \mathrm{dm}^{-3}[\mathrm{NaOAc}]=3.05 \times 10^{-3} \mathrm{~mol} \mathrm{dm}^{-3}$ $\mathrm{CO}=50 \mathrm{~mL} \mathrm{~min}^{-1}$ and air $=50 \mathrm{~mL} \mathrm{~min}^{-1}$ 

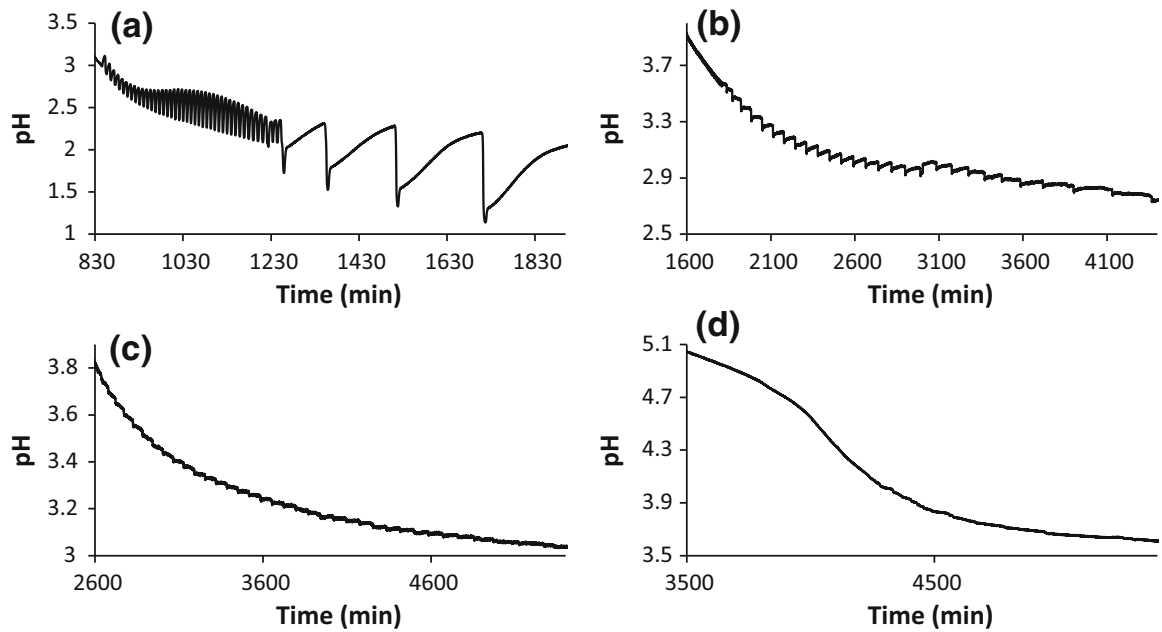

Fig. $3 \mathrm{pH}$ oscillations in the PCPOC reaction at $30{ }^{\circ} \mathrm{C}$ with water volume percent of a $5 \%$; b $20 \%$; c $30 \%$ and d $40 \%$, in which $[\mathrm{PhAc}]=0.124 \mathrm{~mol} \mathrm{dm}^{-3} \quad\left[\mathrm{PdI}_{2}\right]=2.64 \times 10^{-3} \mathrm{~mol} \mathrm{dm}^{-3}$ $[\mathrm{KI}]=0.494 \mathrm{~mol} \mathrm{dm}^{-3} \quad[\mathrm{NaOAc}]=3.05 \times 10^{-3} \quad \mathrm{~mol} \mathrm{dm}^{-3} \quad \mathrm{CO}=50 \mathrm{~mL} \mathrm{~min}^{-1}$ and air $=50 \mathrm{~mL} \mathrm{~min}^{-1}$

Table 2 A summary of trends in the $\mathrm{pH}$ oscillations of the PCPOC reaction at $30{ }^{\circ} \mathrm{C}$ with water volume percent from 0 to $40 \%$

\begin{tabular}{llllll}
\hline Volume percent of $\mathrm{H}_{2} \mathrm{O}(\%)$ & 0 & 5 & 20 & 30 & 40 \\
\hline pH trend at onset of oscillations & Rising & Falling & Falling & Falling & N/A \\
pH at onset of oscillations & 1.75 & 2.99 & 4.35 & 4.23 & N/A \\
Onset time of oscillations (min) & 2421 & 845 & 1351 & 2387 & N/A \\
Oscillations duration (min) & 1190 & 1149 & 2876 & 3122 & N/A \\
Max amplitude (pH units) & 0.61 & 1.19 & 0.10 & 0.03 & N/A \\
Min amplitude (pH units) & 0.003 & 0.17 & 0.018 & 0.007 & N/A \\
Max period (min) & 45 & 277 & 190 & 238 & N/A \\
Min period (min) & 6 & 9 & 5 & 4 & N/A \\
\hline
\end{tabular}

approximately 0.08 at the end of the run. In addition to the decrease in size of oscillations, the oscillatory behavior changed to a more stepwise behavior. With a water volume percent of $30 \%$, the oscillatory behavior was similar to that of the experiment in which the water volume percent was $20 \%$. The oscillations still occurred when the $\mathrm{pH}$ was falling (at a $\mathrm{pH}$ of 4.23), although they took longer to appear (2387 $\mathrm{min}$ ) and stepwise $\mathrm{pH}$ behavior was apparent (Fig. 3c). The maximum period of the oscillations was $25 \%$ greater than that observed at a water volume percent of $30 \%$ but the amplitude of the oscillations was reduced by almost $67 \%$ (Fig. 3b). By the time a water volume percent of $40 \%$ was reached, $\mathrm{pH}$ oscillations were not discernible (Fig. 3d). 
As reactions where conducted in a reaction calorimeter, it was possible to apply power compensation calorimetry to record changes in reaction heat over time $[7,12,13,16]$. Oscillations in heater power were still evident with 5, 20 and 30\% water, were in phase with the $\mathrm{pH}$ oscillations and reflected the changes in the $\mathrm{pH}$ oscillations as shown in Fig. 4. Note the lack of oscillations in Fig. 4e when the volume percent of water is $40 \%$ even though $\mathrm{PhAc}$ conversion remained at $95-100 \%$ in all experiments.

Previous studies of the PCPOC reaction at temperatures from 0 to $40{ }^{\circ} \mathrm{C}$ found that changing the reaction temperature produced changes in the shape of the $\mathrm{pH}$ oscillations [7, 12]. Increasing the water content of the reaction also affects the shape of the $\mathrm{pH}$ oscillations as shown in Table 3.

As the amount of water in the system increased, the oscillations became more step-like in nature (Table 3). When the water volume percent was 5 and 20\%, there was also a sudden change near the end of the reaction from small sinusoidal-type oscillations to large oscillations that were almost square. The recorded $\mathrm{pH}$, including the extent of the initial $\mathrm{pH}$ drop and the final $\mathrm{pH}$ value was dependent on the amount of water in the system-once water was in the system, increasing water content reduced the size of the initial $\mathrm{pH}$ drop and the final $\mathrm{pH}$ reading. While $\mathrm{pH}$ clearly differs between runs, as the measurement of $\mathrm{pH}$ is affected by the composition of the solvent it is difficult to meaningfully compare oscillatory characteristics such as the amplitude of the oscillations between these experiments. This is a consequence of the fact that the standard $\mathrm{pH}$ scale is based on measurements in water. As the amount of organic solvent in the system is increased, it alters the $\mathrm{pK}_{\mathrm{a}}$ of the acid in the system and hence alters the $\mathrm{pH}$ that is observed. It has been reported that in $100 \%$ methanol $\mathrm{pH}$ values can be adjusted by adding 2.3 to the observed $\mathrm{pH}$ measurements to get the equivalent $\mathrm{pH}$ value in water [17]. However, as the solvent composition changes, the amount by which the observed $\mathrm{pH}$ values need to be adjusted also changes [18]. This means that under the conditions used in these experiments a direct comparison of the observed $\mathrm{pH}$ values is challenging. To overcome this issue, the relationship between HI concentration and $\mathrm{pH}$ in the methanol/water/KI systems used in the reactions was determined by adding $\mathrm{HI}$ to methanol/water/KI solutions of the required compositions and measuring the $\mathrm{pH}$. Fig. 5 shows the relationship obtained for each solution.

Employing the data shown in Fig. 5, the best fit curve for each solution composition over the required $\mathrm{pH}$ range was obtained (Table 4) and used to estimate the concentration of $\mathrm{HI}$ produced during the PCPOC experiments from the $\mathrm{pH}$ recorded (Fig. 1). The estimated concentrations of $\mathrm{HI}$ in each of the PCPOC experiments are shown in Fig. 6.

A summary of the trends in the oscillations in HI concentrations in the PCPOC reactions is given in Table 5. In 100\% methanol the initial stage of the reaction is characterized by a large increase in $\mathrm{HI}$ concentration to a maximum of $5.1 \times 10^{-3} \mathrm{~mol} \mathrm{~L}^{-1}$. Oscillations are only apparent once this large concentration has decreased to $1.43 \times 10^{-3} \mathrm{~mol} \mathrm{~L}^{-1}$. The relatively large $\mathrm{pH}$ oscillations $(0.6 \mathrm{pH}$ units, Table 2 and Fig. 2) recorded in $100 \%$ methanol are actually small oscillations in the concentration of HI with a maximum amplitude of $1.78 \times 10^{-4} \mathrm{~mol} \mathrm{~L}^{-1}$ (Fig. 6; Table 5). It is interesting to note that oscillations only commence once the 
(a)

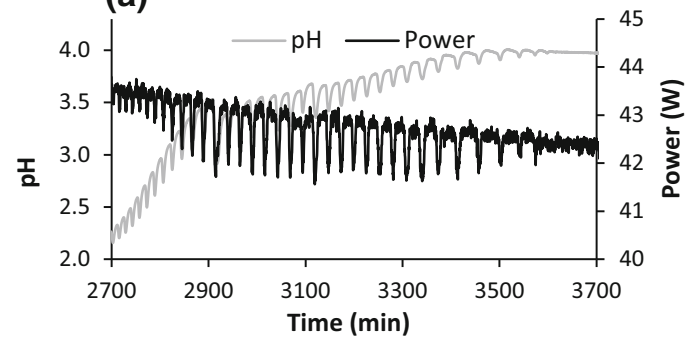

(b)

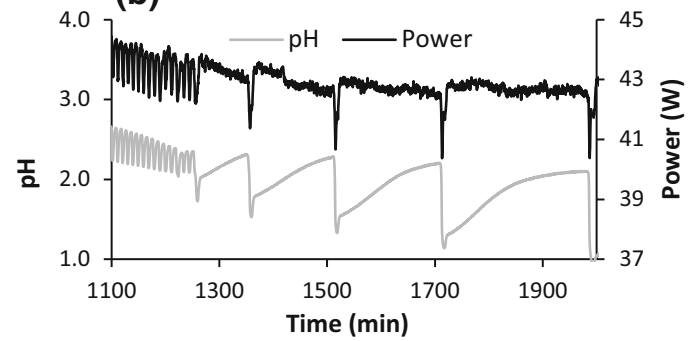

(c)

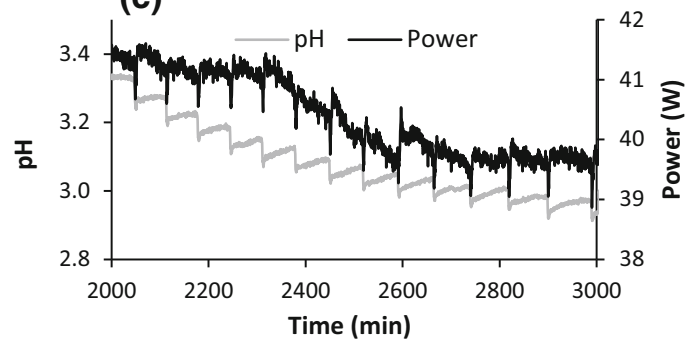

(d)

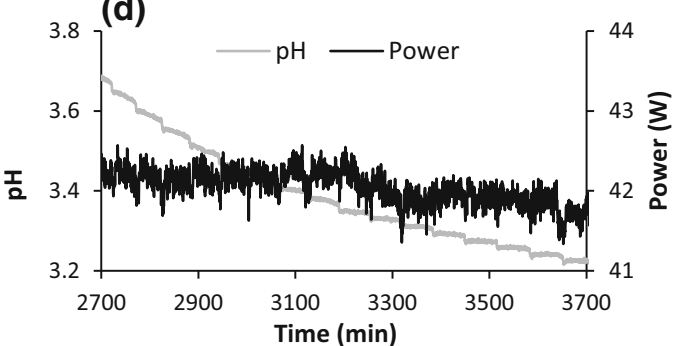

(e)

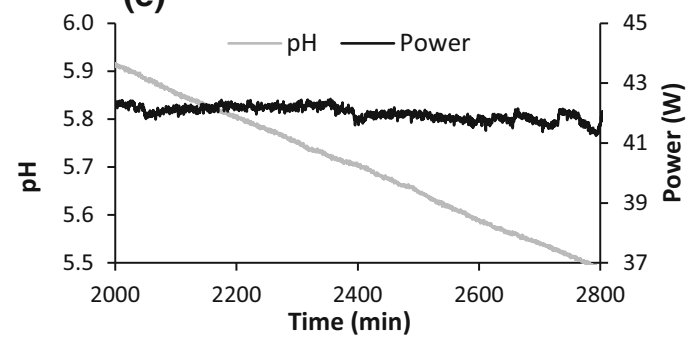


4Fig. 4 The synchronization of oscillations in $\mathrm{pH}$ and heater power in the PCPOC reaction at $30{ }^{\circ} \mathrm{C}$ with water volume percentages of a $0 \%$; b 5\%; c $20 \%$; d $30 \%$ and e $40 \%$, in which $[\mathrm{PhAc}]=0.124 \mathrm{~mol} \mathrm{dm}^{-3}$ $\left[\mathrm{PdI}_{2}\right]=2.64 \times 10^{-3} \mathrm{~mol} \mathrm{dm}^{-3} \quad[\mathrm{KI}]=0.494 \mathrm{~mol} \mathrm{dm}^{-3} \quad[\mathrm{NaOAc}]=3.05 \times 10^{-3} \mathrm{~mol} \mathrm{dm}^{-3}$ $\mathrm{CO}=50 \mathrm{~mL} \mathrm{~min} \operatorname{mon}^{-1}$ and air $=50 \mathrm{~mL} \mathrm{~min}^{-1}$

Table 3 The change in shape of $\mathrm{pH}$ oscillations as water volume percent was increased from 0 to $30 \%$ in the PCPOC reaction at $30{ }^{\circ} \mathrm{C}$

\section{$\mathrm{H}_{2} \mathrm{O}$ volume percent Oscillation waveforms \\ $(\%)$}

0

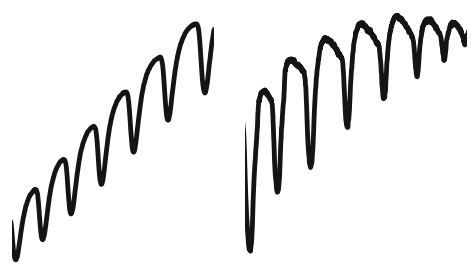

5

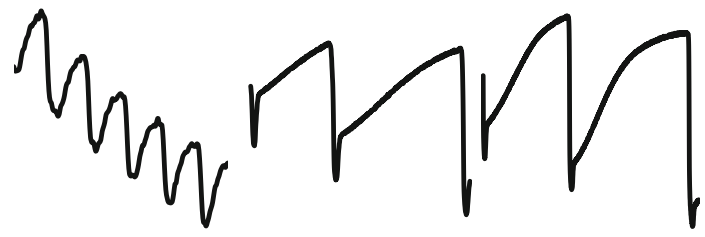

20
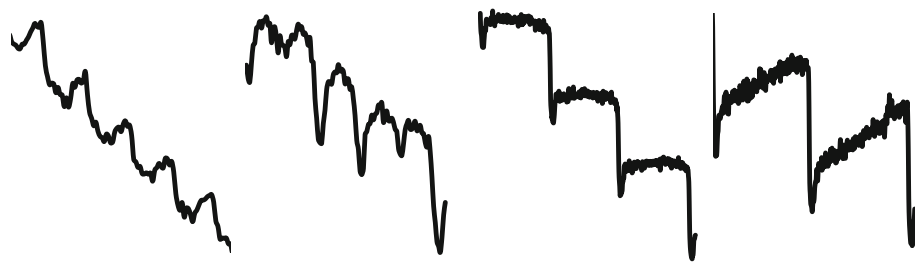

30

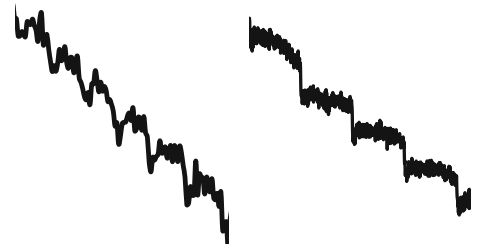

HI concentration is in the region of $1 \times 10^{-3} \mathrm{~mol} \mathrm{~L}^{-1}$. As the amount of water in the system increases the concentration of $\mathrm{HI}$ when oscillations start reduces. Once water is present in the system it suppresses the initial formation of $\mathrm{HI}$, resulting in a slower autocatalytic process. 


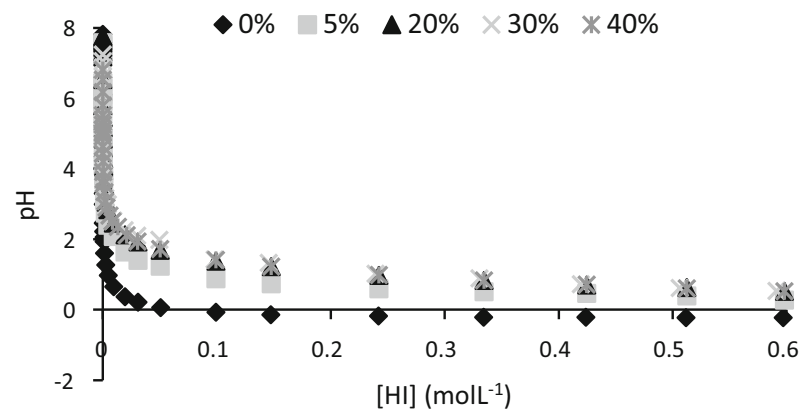

Fig. $5 \mathrm{pH}$ recorded on the addition of $\mathrm{HI}$ to methanol/water/KI solution with water volume percent from 0 to $40 \%$

Table 4 Relationship between [HI] and $\mathrm{pH}$ for methanol/water/ KI solutions with water volume percent from 0 to $40 \%$

\begin{tabular}{ll}
\hline $\mathrm{H}_{2} \mathrm{O}$ Vol percent $(\%)$ & Equation \\
\hline 0 & {$[H I]=0.0587(p H+1)^{-3.631}$} \\
5 & {$[H I]=0.0618(p H)^{-3.643}$} \\
20 & {$[H I]=0.8192(p H)^{-4.884}$} \\
30 & {$[H I]=3.3342(p H)^{-6.199}$} \\
40 & {$[H I]=3.9974(p H)^{-6.643}$}
\end{tabular}

(a)

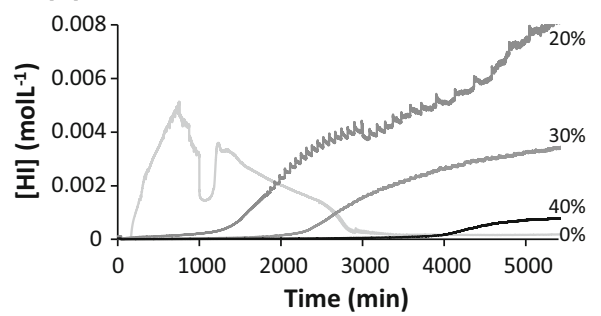

(b)

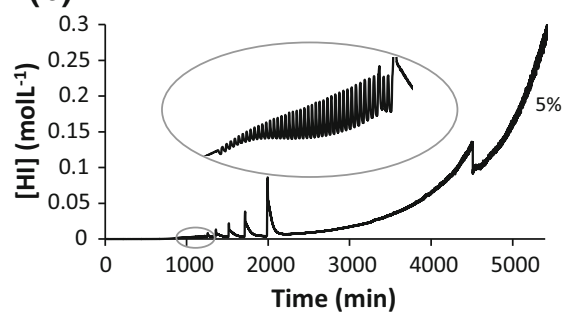

Fig. 6 Estimated $[\mathrm{HI}]$ concentrations in the $\mathrm{PCPOC}$ reaction at $30{ }^{\circ} \mathrm{C}$ with water volume percent of a 0 , 20,30 and $40 \%$ and b $5 \%$, with $[\mathrm{PhAc}]=0.124 \mathrm{~mol} \mathrm{dm}^{-3}\left[\mathrm{PdI}_{2}\right]=2.64 \times 10^{-3} \mathrm{~mol} \mathrm{dm}^{-3}$ $[\mathrm{KI}]=0.494 \mathrm{~mol} \mathrm{dm}^{-3} \quad[\mathrm{NaOAc}]=3.05 \times 10^{-3} \mathrm{~mol} \mathrm{dm}^{-3} \quad \mathrm{CO}=50 \mathrm{~mL} \mathrm{~min}^{-1}$ and air $=50 \mathrm{~mL} \mathrm{~min}^{-1}$

Table 5 A summary of trends in the oscillations in $[\mathrm{HI}]$ in the PCPOC reaction at $30{ }^{\circ} \mathrm{C}$ with water volume percent from 0 to $40 \%$

\begin{tabular}{llllll}
\hline Volume percent of $\mathrm{H}_{2} \mathrm{O}(\%)$ & 0 & 5 & 20 & 30 & 40 \\
\hline $\begin{array}{l}\text { [HI] trend at onset of } \\
\text { oscillations }\end{array}$ & Falling & Rising & Rising & Rising & N/A \\
$\begin{array}{l}\text { [HI] at onset of oscillations } \\
\left.(\mathrm{mol} \mathrm{L})^{-1}\right)\end{array}$ & $1.43 \times 10^{-3}$ & $1.10 \times 10^{-3}$ & $9.36 \times 10^{-4}$ & $4.34 \times 10^{-4}$ & N/A \\
$\begin{array}{llll}\text { Max amplitude }\left(\mathrm{mol} \mathrm{L}^{-1}\right) \\
\text { Min amplitude }\left(\mathrm{mol} \mathrm{L}^{-1}\right)\end{array}$ & $1.78 \times 10^{-4}$ & $8.18 \times 10^{-2}$ & $4.22 \times 10^{-4}$ & $1.20 \times 10^{-4}$ & N/A \\
\end{tabular}




\section{Conclusions}

This study has found that oscillations in $\mathrm{pH}$ and reaction heat are still observable when the volume of water in the PCPOC reaction is increased up to $30 \%$ water. On the strength of this finding, optimization of the reaction conditions in mixtures with water would be beneficial in order to further the development of applications of this reaction, for example, using polymeric substrates in this reaction for medical applications. Solvent composition affects the $\mathrm{pH}$ measurement so direct comparison of the $\mathrm{pH}$ in the different solvent compositions is not meaningful. However, by establishing the relationship between $\mathrm{HI}$ concentration and the observed $\mathrm{pH}$ at each solvent composition it has been possible to estimate the change in concentration of HI during the reaction. This has shown that, under the initial conditions studied, as the concentration of water in the system increases HI formation is suppressed until, at $40 \%$ water, oscillations cease. It has also shown that oscillations commence when the $\mathrm{HI}$ concentration is in the region of $1 \times 10^{-3} \mathrm{~mol} \mathrm{~L}^{-1}$, with this value slightly decreasing as water concentration increases.

Acknowledgements The authors wish to acknowledge the UK Engineering and Physical Sciences Research Council (EPSRC) Grant no. EP/H003908/1 for funding this research. Dr Julie Parker would like to acknowledge Professor Allen Wright for funding her Ph.D. studies. Data supporting this publication is openly available under an 'Open Data Commons Open Database License'. Additional metadata are available at: http://dx.doi.org/10.17634/082584-2. Please contact Newcastle Research Data Service at rdm@ncl.ac.uk for access instructions.

Open Access This article is distributed under the terms of the Creative Commons Attribution 4.0 International License (http://creativecommons.org/licenses/by/4.0/), which permits unrestricted use, distribution, and reproduction in any medium, provided you give appropriate credit to the original author(s) and the source, provide a link to the Creative Commons license, and indicate if changes were made.

\section{References}

1. Gorodskii SN, Kalenova ES, Bruk LG, Temkin ON (2003) Oxidative carbonylation of alkynes in self-oscillating mode. Effect of the nature of substrates on the dynamic behavior of reaction system. Russ Chem Bull 52(7):1534-1543

2. Gorodskii SN, Zakharov AN, Kulik AV, Bruk LG, Temkin ON (2001) Oxidative carbonylation of alkynes in an oscillation mode: I. Concentration limits for oscillations in the course of phenylacetylene carbonylation and possible mechanisms of the process. Kinet Catal 42(2):251-263

3. Malashkevich AV, Bruk LG, Temkin ON (1997) New oscillating reaction in catalysis by metal complexes: a mechanism of alkyne oxidative carbonylation. J Phys Chem A 101(51):9825-9827

4. Isakova A, Novakovic K (2017) Oscillatory chemical reactions in the quest for rhythmic motion of smart materials. Eur Polym J. doi:10.1016/j.eurpolymj.2017.08.033

5. Donlon L, Novakovic K (2014) Oscillatory carbonylation using alkyne-functionalised poly(ethylene glycol). Chem Commun 50(98):15506-15508

6. Parker J (2016) A study of the phenylacetylene oxidative carbonylation reaction in oscillatory and non-oscillatory modes. Doctoral Thesis, Newcastle University, Newcastle Upon Tyne, UK, Newcastle University, Newcastle Upon Tyne, UK

7. Parker J, Novakovic K (2016) Autonomous reorganization of the oscillatory phase in the $\mathrm{PdI}_{2}$ catalyzed phenylacetylene carbonylation reaction. React Kinet Mech Cat 118(1):73-85 
8. Mukherjee A (2009) Analysis and control of oscillations and chaos in reactions. PhD, Newcastle University

9. Parker J, Novakovic K (2013) Influence of water and the reactant addition sequence on palladium(II) iodide-catalyzed phenylacetylene carbonylation. Ind Eng Chem Res 52(7):2520-2527

10. Novakovic K, Parker J (2011) Catalyst initiation in the oscillatory carbonylation reaction. Int J Chem Eng. doi: $10.1155 / 2011 / 518592$

11. Gabriele B, Costa M, Salerno G, Chiusoli GP (1994) An efficient and selective palladium-catalysed oxidative dicarbonylation of alkynes to alkyl- or aryl-maleic esters. J Chem Soc Perkin Trans $1: 83-87$

12. Novakovic K, Mukherjee A, Willis MJ, Wright AR, Scott SK (2009) The influence of reaction temperature on the oscillatory behaviour in the palladium-catalysed phenylacetylene oxidative carbonylation reaction. PCCP 11:9044-9049

13. Parker J, Novakovic K (2017) The effect of temperature on selectivity in the oscillatory mode of the phenylacetylene oxidative carbonylation reaction. ChemPhysChem 18:1981-1986

14. Brandariz I, Barriada JL, Taboada-Pan C, de Vicente MES (2001) Estimating the change in liquid junction potential on glass electrodes. Electroanalysis 13(13):1110-1114

15. Brandariz I, Vilariño T, Alonso P, Herrero R, Fiol S, Sastre de Vicente ME (1998) Effect of ionic strength on the formal potential of the glass electrode in various saline media. Talanta 46(6):1469-1477

16. Novakovic K, Grosjean C, Scott SK, Whiting A, Willis MJ, Wright AR (2007) Achieving pH and Qr oscillations in a palladium-catalysed phenylacetylene oxidative carbonylation reaction using an automated reactor system. Chem Phys Lett 435(1-3):142-147

17. Porras SP, Kenndler E (2004) Kenndler E (2004) Capillary zone electrophoresis in non-aqueous solutions: $\mathrm{pH}$ of the background electrolyte. J Chromatogr A 1037(1-2):455-465

18. Rosés M (2004) Determination of the $\mathrm{pH}$ of binary mobile phases for reversed-phase liquid chromatography. J Chromatogr A 1037(1-2):283-298 